\title{
Tinea Corporis Caused by Trichophy- ton Benhamiae Transmitted by a Dog: First Case Report in Portugal
}

\section{Tinea Corporis Causada por Trichophyton Benhamiae de Transmissão Canina: Primeiro Relato em Portugal}

Ermelindo Tavares ${ }^{1 *}$, Raquel Sabino², Helena Simões ${ }^{2}$, Cristina Veríssimo², Esperança Ussene ${ }^{3}$

\section{ABSTRACT}

Dermatophytoses are superficial and contagious infections caused by dermatophyte fungi. They are the most frequent infectious dermatosis in clinical practice, and can affect the skin, hair and nails. Its correct diagnosis allows the understanding of clinical, ecological and epidemiological aspects associated with these microorganisms. Clinical presentation is variable and depends on the habitat (human, animal or soil origin), virulence of the fungus and on the host's immune status.

We report the clinical case of a 62-year-old man with tinea corporis, which stands out for its exuberant clinical presentation and by the isolated agent, Trichophyton benhamiae (formerly known as Arthroderma benhamiae), an etiological agent of dermatophytosis that has not been scientifically reported in Portugal yet.

KEYWORDS: Adult; Animals, Domestic; Arthrodermataceae; Dermatomycoses; Dogs; Tinea

1. Department of Dermatology and Venereology, Vila Franca de Xira Hospital, Vila Franca de Xira, Portugal. 2. Department of Infectious Diseases, National Reference Laboratory for Parasitic and Fungal Infections, National Institute of Health Dr. Ricardo Jorge, Lisbon, Portugal. 3. Department of Pathology, Vila Franca de Xira Hospital, Vila Franca de Xira, Portugal. 


\section{RESUMO}

As dermatofitoses ou tinhas (tinea do latim) são infeções superficiais e contagiosas causadas por fungos dermatófitos. São as dermatoses infeciosas mais frequentes na prática clínica, podendo afetar a pele, o cabelo e as unhas. O seu correto diagnóstico permite compreender os aspetos clínicos, ecológicos e epidemiológicos relacionados com estes microrganismos. A apresentação clínica é variável e depende do habitat (origem humana, animal ou solo), da virulência do fungo e do estado imunológico do hospedeiro.

Relata-se o caso clínico de um homem de 62 anos com tinea corporis, que se destaca pela sua apresentação clínica exuberante e pelo agente isolado, Trichophyton benhamiae (anteriomente designado Arthroderma benhamiae), um agente etiológico de dermatofitose ainda sem relato científico em Portugal.

PALAVRAS-CHAVE: Adulto; Animais Domésticos; Arthrodermataceae; Cão; Dermatomicoses; Tinha

\section{INTRODUCTION}

Dermatophytes are keratinophilic filamentous fungi that cause skin, nail and hair infections in animals and humans. Those infections are designated as dermatophytosis, ringworm (Latin - tinea) or even as epidermophytosis. In what concerns to taxonomy, dermatophytes are now classified in seven genera: Trichophyton (T.), Epidermophyton, Microsporum (M.), Nannizzia, Paraphyton, Lophophyton and Arthroderma (A.). The genus Trichophyton is the most frequently isolated in man. According to their habitat, dermatophytes are classified into anthropophilic fungi (infecting almost exclusively the man, with mild or even absent inflammatory reaction), zoophilic (infecting animals and, accidentally, man, with moderate to severe inflammatory reaction) and geophilic (found predominantly in the soil, infecting humans and animals, with moderate to severe inflammatory reaction). ${ }^{1,2}$

A. benhamiae (basonym) is a zoophilic dermatophyte whose main reservoir is the guinea pig, in which it can cause hair and nail infections. The first case of dermatophytosis in humans caused by this specie was reported in Japan in 2002. Since then, it has been isolated in skin, hair and nail dermatophytosis in Northern Europe and the American continent. For many years, this fungus was considered as a Trichophyton species and integrated in the T. mentagrophytes complex. ${ }^{2-5}$ In the work published in 2017 by de Hoog et al, ${ }^{1}$ based on the sequencing of the ribosomal DNA, this microorganism was renamed as T. benhamiae.

\section{CASE REPORT}

A 62-year-old man, Caucasian, carpenter, with obesity and dyslipidemia treated with atorvastatin was ob- served in the dermatology consultation due to an erythematous and scaly dermatosis with three weeks of evolution. On March 20 th 2020 (day zero) he referred direct contact with a portuguese podengo dog (Canis lupus familiaris) that presented a wound on its left posterior leg. On March 30 ${ }^{\text {th }}$, 2020 (day 10 post-contact) he noticed the appearance of erythematous papules and pustules on the upper and lower limbs that increased in diameter resulting in round and oval scaly cutaneous plaques with vesicles and pustules on the periphery and blisters that quickly ruptured releasing a purulent exudate. The lesions were pruritic, and the patient had no complaints regarding other organs and systems. The animal was not taken to the vet for clinical evaluation. Its wound was washed at home with $0.4 \%$ sodium hypochlorite solution with complete resolution in 14 days. The patient denied contact with other pets.

By the day the patient was observed in our department (day 31 post-contact) the dermatological examination revealed, in the right leg, a dermatosis characterized by an erythematous, scaly plaque, with more than 10 $\mathrm{cm}$ diameter, with an annular border with vesicles and pustules and slightly scaly center. More than ten round and oval plaques with 3 to $5 \mathrm{~cm}$ diameter with erythematous and violet edges were also observed. The majority of them are coalescent and cutaneous detachment and blisters with purulent exudate content were also detected (Fig. 1). In the thighs and forearms, five erythematous, round and oval plaques, with 1 to $2 \mathrm{~cm}$ diameter were also present. No lesions were found in the scalp, face and nails. The overall examination was normal. The hypothesis of diagnosis was tinea corporis.

Incisional biopsy was performed in the right leg for histological examination and direct immunofluorescence (DIF). The first was compatible with tinea corporis, with 


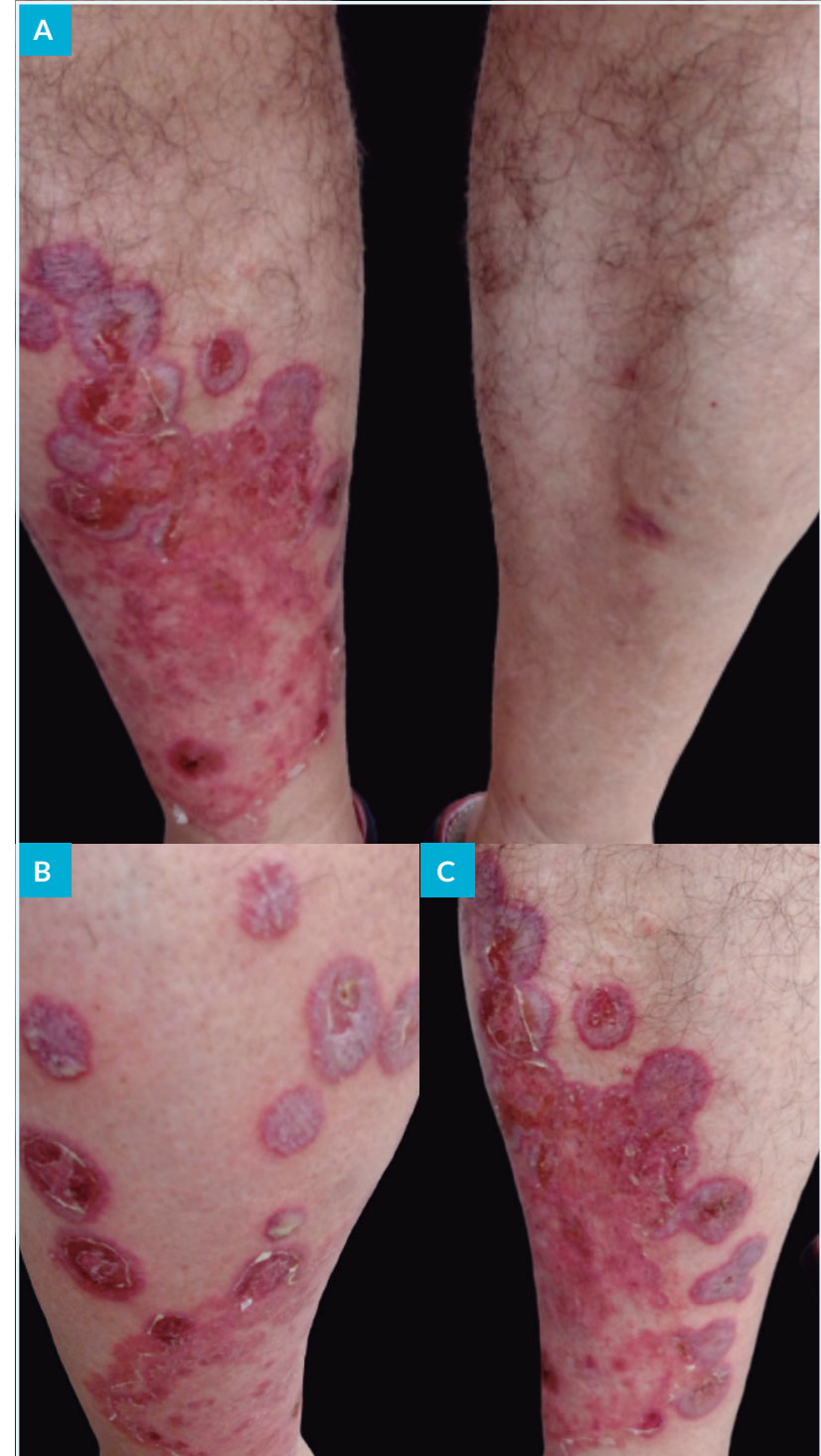

FIGURE 1. Tinea corporis: clinical features. Erythematous plaque with desquamated center, annular and circular rim containing vesicles and pustules on the right leg (A, B). Blister with purulent exudate (B). Round and oval plate and skin detachment (A-C).

observation of acanthosis, compact hyperkeratosis, focal orthokeratosis, few neutrophils and hyphae (positive reaction with periodic acid-Schiff staining) in the stratum corneum and a mild chronic superficial perivascular lymphocytic inflammation with few eosinophils in the dermis (Fig. 2). The DIF examination was negative. The bacteriological culture of the purulent exudate did not reveal any pathogens.

Skin scales were collected for mycological examination, revealing spores in the direct examination with $\mathrm{KOH}$ 30\%. Sample was inoculated onto Sabouraud dextrose agar (SDA) with chloramphenicol 0.05\%, Sabouraud broth with chloramphenicol $0.05 \%$ and mycosel agar and incubated at $27^{\circ} \mathrm{C}$ for three weeks. The obtained culture revealed a white cottony colony with yellowish reverse with morphological characteristics compatible

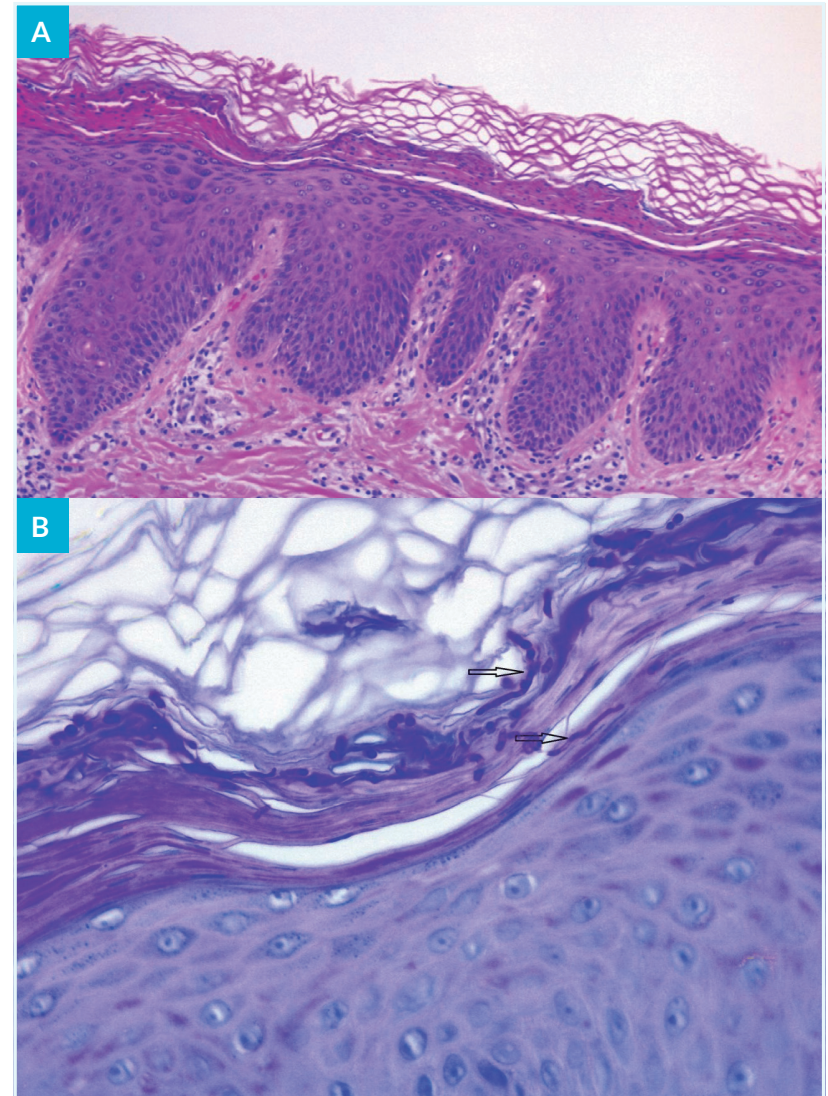

FIGURE 2. Tinea corporis: histopathological features. Acanthosis, compact hyperkeratosis, orthokeratosis and neutrophils are observed in the epidermis and perivascular lymphocytic inflammation is observed in the dermis (A) (hematoxylin and eosin staining, 10x). Hyphae (black arrows) are present in the stratum corneum (B) (periodic acid-Schiff staining, 40x).

with T. benhamiae (Fig. 3). Identification was obtained by MALDI-TOF MS (MAtrix-assisted laser desorption/ ionization time-of-flight mass spectrometry) with a confidence level of $99.9 \%$. Confirmation was done by molecular method. Total genomic DNA was extracted from purified colonies. The internal transcribed spacer (ITS) region of ribosomal DNA ( $\mathrm{rDNA}$ ) was amplified using the primer set ITS1 and ITS4. Sequencing was performed and nucleotide sequences were edited using the program Chromas 2 and aligned using the program CLUSTAL X2. The obtained sequence was compared with sequences deposited in the NCBI and Westerdijk Fungal Biodiversity Institute - KNAW databases, resulting in identification of T. benhamiae ( $97 \%$ homology). The obtained sequence was deposited in GenBank with the accession number MT956947 and the isolated strain is referenced as Tb2020HVFX.

Treatment was instituted using oral terbinafine 250 $\mathrm{mg} /$ day, four weeks and diflucortolone valerate $0.1 \%+$ isoconazole nitrate $1 \%$ cream twice a day, one week, followed by omoconazole nitrate $1 \%$ cream once a day, two weeks. Complete remission was observed at the end of the treatment period. 

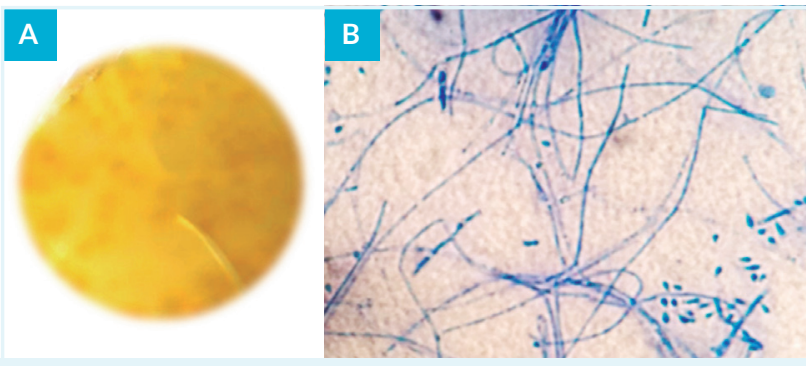

FIGURE 3. T. benhamiae. Macroscopic appearance (mycosel agar): yellowish reverse (A). Microscopic feature (toluidine blue staining, x10): micronidia are present and no spiral hyphae are observed (B)

\section{DISCUSSION}

To the best of the authors' knowledge, this is the first report on dermatophytosis caused by T. benhamiae in Portugal.

T. benhamiae is a zoophilic fungus and is an etiologic agent of tinea corporis, faciei, manuum and capitis. This specie causes moderate to severe inflammatory skin reaction in man, in particular in children, teenagers and immunocompromised patients. Its natural reservoir is the guinea pig, but it is occasionally isolated from rabbits, dogs and cats. The infection is usually found in these animals and in persons who adopt them as pets. The first report of ringworm caused by this species was from Japan. Subsequently, cases in Northern Europe and South America have been emerging. ${ }^{1-5}$

The taxonomic classification of fungi has undergone major changes in recent decades. For several years, classification was based on clinical, morphological and physiological features of the isolates. As such, T. benhamiae was initially considered as part of the T. mentagrophytes complex and was classified as A. benhamiae (anamorph). However, the development and improvement of molecular methods based on the sequencing of ribosomal DNA led to a huge revolution in fungal taxonomy, in particular in dermatophytes. $2,6,7$

Identification of T. benhamiae is a complex laboratorial process. As such, the definitive diagnosis must be obtained by combining several techniques, namely conventional mycological methods (direct examination, culture followed by colonies's macroscopic and microscopic observation and enzymatic profile), molecular methodologies and technologies based on protein profile (MALDI-TOF MS). 2,5 Conventional methods do not allow, in some cases, the differentiation between morphologically similar dermatophytes.

Two phenotypes have been described for T. benhamiae: yellow and white. In the first, the colonies grow slowly, have pleated mycelium and have an orange-yellow reverse. In SDA media, no macroconidia or spiral hyphae are found and microconidia are rare. The main differential diagnosis is M. canis, which has also yellowish colonies and present thick walled macronidia with 6-12 cells and thin septa. The white phenotype shows fast growing, sprayed, flocose colonies with yellow, orange or brown reverse color. Spiral hyphae are present in some cases and many spherical or clavated microconidia are observed; macroconidia are fewer, clavated and cigar-shaped, with 3-8 cells with smooth and thin walls. The main differential diagnosis is T. mentagrophytes, which present several spherical microconidia, spiral hyphae and clavated, cigar-shaped macroconidia. ${ }^{8-13}$

The diagnosis of dermatophytosis is usually clinical. However, based on clinical presentation there is no differentiation between lesions caused by $T$. benhamiae and other dermatophytes, particularly the zoophilic one. Therefore, the confirmation of $T$. benhamiae should be obtained with the methods mentioned above. Furthermore, complementary diagnostic methods such as histology, cutaneous DIF and bacteriological examination can be extremely important in the exclusion of other infectious and non-infectious dermatoses namely nummular and stasis eczema, impetigo, subacute cutaneous lupus erythematosus, Hansen's disease, pemphigus, granuloma annulare, psoriasis and erythema annulare centrifugum. ${ }^{14}$

Topical antifungals are the first-line treatment for localized and non-complicated tinea corporis and faciei and should be applied for at least two weeks until complete clearance of the infection. Cases of extensive tinea corporis, tinea manuum, capitis, unguium and barbae require topical and systemic treatment. Oral terbinafine, itraconazole and fluconazole are generally effective alternatives. Adverse effects with different levels of severity may occur. The duration of the treatment depends on the location and extent of the infection, varying between one and six weeks. Associations of topical antifungals and steroids are important in cases of moderate or severe inflammation. They should be used with caution and for a short period to avoid striae, skin atrophy and secondary bacterial infections. The remaining treatment is carried out with topical antifungal alone. Preference should be given to low-potency topical steroids, particularly in the face and skin folds. The use of systemic steroids occurs in cases of tinea capitis with severe inflammation (Kerion celsi). ${ }^{14}$

In conclusion, the adoption of peculiar species as pets may have serious public health implications. T. benham- 
iae is an example of that, with an increasing recognition as agent of zoophilic ringworm. As in Northern Europe, the prevalence of this infection in Portugal is very likely to increase. Therefore, it is essential to consider pets as a potential source of infections and to treat them appropriately together with their owners in order to avoid recurrences, interpersonal and inter-animal transmission.

\section{RESPONSABILIDADES ÉTICAS}

CONFLITOS DE INTERESSE: Os autores declaram a inexistência de conflitos de interesse na realização do presente trabalho.

FONTES DE FINANCIAMENTO: Não existiram fontes externas de financiamento para a realização deste artigo.

CONFIDENCIALIDADE DOS DADOS: Os autores declaram ter seguido os protocolos da sua instituição acerca da publicação dos dados de doentes.

CONSENTIMENTO: Consentimento do doente para publicação obtido.

PROVENIÊNCIA E REVISÃO POR PARES: Não comissionado; revisão externa por pares.

\section{ETHICAL DISCLOSURES}

CONFLICTS OF INTEREST: The authors have no conflicts of interest to declare.

FINANCING SUPPORT: This work has not received any contribution, grant or scholarship.

CONFIDENTIALITY OF DATA: The authors declare that they have followed the protocols of their work center on the publication of data from patients.

PATIENT CONSENT: Consent for publication was obtained.

PROVENANCE AND PEER REVIEW: Not commissioned; externally peer reviewed.

\section{REFERENCES}

1. de Hoog GS, Dukik K, Monod M, Packeu A, Stubbe D, Hendrickx M, et al. Toward a novel multilocus phylogenetic taxonomy for the dermatophytes. Mycopathologia. 2017;182:5-31. doi:10.1007/s11046-016-0073-9.

2. Sabou M, Denis J, Boulanger N, Forouzanfar F, Glatz I, Lipsker $D$, et al. Molecular Identification of Trichophyton Benhamiae in Strasbourg, France: A 9-year Retrospective Study. Med Mycol. 2018;56:723-34. doi:10.1093/mmy/myx100.

3. Mochizuki T, Kawasaki M, Ishizaki H, Kano R, Hasegawa A, Tosaki H, et al. Molecular epidemiology of Arthroderma benhamiae an emerging pathogen of dermatophytoses in Japan, by polymorphisms of the non-transcribed spacer region of the ribosomal DNA. J Dermatol Sci. 2001;27:14-20. doi:10.1016/ S0923-1811(01)00101-3.
4. El-Heis S, Borman AM, Szekely A, Godfrey KM. Tinea Corporis Caused by Arthroderma Benhamiae in a Child. Clin Exp Dermatol. 2016;41:955-7. doi:10.1111/ced.12966.

5. Nakamura Y, Kano R, Nakamura E, Saito K, Watanabe S, Hasegawa A. Case Report. First report on human ringworm caused by Arthroderma benhamiae in Japan transmitted from a rabbit. Mycoses. 2002;45:129-131. doi:10.1046/j.14390507.2002.00732.x.

6. Heidemann S, Monod M, Graser Y. Signature polymorphisms in the internal transcribed spacer region relevant for the differentiation of zoophilic and anthropophilic strains of Trichophyton interdigitale and other species of T. mentagrophytes sensu lato. Br J Dermatol. 2010;162:282-95. doi:10.1111/ j.1365-2133.2009.09494.x.

7. Kawasaki M. Verification of a taxonomy of dermatophytes based on mating results and phylogenetic analyses. Med Mycol. 2011;52:291-95. doi:10.3314/mmj.52.291.

8. Symoens F, Jousson O, Packeu A, Fratti M, Staib P, Mignon B, et al. The dermatophyte species Arthroderma benhamiae: intraspecies variability and mating behaviour. J Med Microbiol. 2013;62:377-85. doi:10.1099/jmm.0.053223-0.

9. Contet-Audonneau N, Leyer C. Emergence of a dermatophyte contracted from guinea pig and close to Trichophyton mentagrophytes var. erinacei: T. mentagrophytes var. porcellae. J Med Mycol. 2010;20:321-5. doi:10.1016/j.mycmed.2010.08.001.

10. Khettar L, Contet-Audonneau N. Cochon d'Inde et dermatophytose. Ann Dermatol Venereol. 2012;139:631-5. doi:10.1016/j.annder.2012.05.007.

11. Hiruma J, Kano R, Harada K, Monod M, Hiruma M, Hasegawa A, et al. Occurrence of Arthroderma benhamiae genotype in Japan. Mycopathologia. 2015;179:219-23. doi:10.1007/ s11046-014-9839-0.

12. Monod M, Fratti M, Mignon B, Baudraz-Rosselet F. Dermatophytes transmis par les animaux domestiques. Rev Med Suisse. 2014;10:749-53.

13. Nenoff P, Uhrlaß S, Kruger C, Erhard M, Hipler UC, Seyfarth F, et al. Trichophyton species of Arthroderma benhamiae - a new infectious agent in dermatology. J Dtsch Dermatol Ges. 2014;12:571-81. doi:10.1111/ddg.12390.

14. Elewski BE, Hughey LC, Sobera JO, Hay R. Fungal diseases (Cap. 77). In: Bolognia JL, Jorizzo JL, Rapini LP, editors. Dermatology. $3^{\text {rd }}$ ed. London: Elsevier; 2012. pag: 1251-84. 